\title{
АКТУАЛЬНЫЕ ВОПРОСЫ ФОРМИРОВАНИЯ СТРАТЕГИИ ФИНАНСИРОВАНИЯ БИЗНЕСА В СОВРЕМЕННЫХ УСЛОВИЯХ
}

\author{
(C) 2020 Подгорная Алла Игоревна \\ кандидат экономических наук, доцент кафедры управления корпоративными финансами, \\ Института управления, экономики и финансов \\ Казанский (Приволжский) федеральный университет, Россия, Казань \\ E-mail: oreola77@mail.ru
}

\section{(C) 2020 Грудина Светлана Игоревна}

кандидат экономических наук, доцент кафедры финансового менеджмента, Института управления, экономики и финансов

Казанский (Приволжский) федеральный университет, Россия, Казань

E-mail:switki@yandex.ru

\section{(c) 2020 Фатхуллин Альберт Рашитович}

доцент кафедры управления человеческими ресурсами

Казанский (Приволжский) федеральный университет, Россия, Казань

Данная статья посвящена актуальной проблеме выбора стратегии финансирования бизнеса. Неэффективное управление оборотным капиталом, а также ограниченность решений, способно в негативном ключе повлиять на финансовую устойчивость бизнеса. В статье исследуются актуальные научные дискуссии относительно применения стратегий и моделей финансирования бизнеса. Авторами исследовано влияние ситуации пандемии 2020 на выбор стратегии финансирования. Определены основные преимущества и недостатки имеющихся моделей финансирования. Выявлены факторы, влияющие на эффективность выбранной стратегии финансирования. Рассмотрены возможности выбора инструментов долгового финансирования бизнеса, основные виды стратегий финансирования оборотных активов, выявлены универсальная стратегия финансирования на примере среднего бизнеса и факторы, которые влияют на выбор стратегии финансирования оборотного капитала.

Ключевые слова: стратегия финансирования, модели финансирования, оборотный капитал, финансовый менеджмент, долговое финансирование, издержки финансовой неустойчивости, финансовые ресурсы.

Актуальность вопроса выбора стратегии финансирования бизнеса в российских компаниях остается острой и требует разностороннего рассмотрения [2]. В условиях пандемии 2020 необходимы не традиционные решения, поскольку использование кредитов от банка не всегда приемлемо. Кредитные инструменты, которые компании могут выбрать для получения доступа к финансированию развиваются и их выбор должен предопределяет финансовая стратегия. Настоящее время, которое можно охарактеризовать как время кризиса, цифровой трансформации, существенных перемен, имеет тенденцию снижения объемов оборотных средств в бизнесе. Во-первых, изменилась структура собственных оборотных средств. Особые условия, поддерживаемые на государственном уровне, привели к увеличению дебиторской задолженности, по самым благоприятным прогнозам к концу 2020 года как минимум в два раза. Во-вторых, возрос риск утраты собственных оборотных средств изза убытков, разорения малого и среднего бизнеса, как следствие ведущие к появлению безнадежной дебиторской задолженности. В третьих, трансформировалась структура источников оборотных средств. Собственные источники значительно снизились из-за снижения оборота и выручки, что компенсировалось дотациями и заемными источниками. На сегодняшний день привлеченные источники финансирования, в различных объемах, есть в каждой компании. Встает вопрос пересмотра стратегии финансирования, учитывающей современные факторы, такие, как ускоренная цифровизация экономи- 
ки, изменения спроса в связи с режимом карантина, изменение структуры игроков на рынке, расширение кредитных инструментов.

Цель данной статьи - выявление факторов, влияющих на выбор стратегии и модели финансирования в России. При проведении исследования качестве инструментария использовались следующие методы научного познания:

- статистические,

- экономического анализа,

- анализа и синтеза,

- системного подхода к изучению внешней и внутренней среды бизнеса, социальноэкономических явлений и процессов.

- общенаучные методы познания,

- индукции и дедукции.

В процессе исследования нами рассмотрены основные виды стратегий финансирования бизнеса, выявлена универсальная стратегия финансирования оборотного капитала на примере среднего бизнеса, определены наиболее важные факторы, определяющие выбор стратегии финансирования бизнеса. Рассмотрим специфику существующих стратегий. Умеренная, или компромиссная, стратегия предполагает хеджированный способ финансирования [3]. Сроки поступления денежных средств и сроки погашения обязательств совпадают [4]. В условиях пандемии, данная стратегия имеет свои преимущества, однако в классическом варианте остается довольно рискованной.

Агрессивная стратегия финансирования бизнеса предполагает использование преимущественно краткосрочного кредитования для финансирования постоянной части активов бизнеса, что должно быть пересмотрено в текущих условиях. Постоянный капитал обеспечивает финансирование только основных средств при высоко агрессивной стратегии [5]. Данная стратегия предполагает самый высокий уровень прибыли и риска. В условиях неопределенности, данный уровень приемлем, на наш взгляд, только при качественном анализе спроса и достаточно сильной кредитной позиции.

Консервативную стратегию финансирования бизнеса в современных условиях может позволить себе очень ограниченная часть бизнеса. Минимальные риски, высокая финансовая устойчивость при минимальной прибыльности доступно для развитого крупного бизнеса, что на сегодняшний день является, скорее исключением, поэтому не входит в объект данного исследования. Мы считаем, что объем потребности в привлечении краткосрочных источников финансирования отражает только выбор классической стратегии финансирования бизнеса, что не учитывает современных условий, требований и возможностей. На наш взгляд, классические стратегии финансирования трансформируются и останутся в ближайшем будущем только в теоретической части финансового менеджмента. Тем не менее, до начала периода неопределенности и пандемии Г. Ф. Токарева и И. В. Багаутдинова [6] предложили использовать комплексную модель управления финансированием. Выявив недостатки идеальной, агрессивной, консервативной моделей комплексный подход, хоть и более сложен, уменьшает риски предыдущих моделей [7]. Также в теории практике можно выделить модель Башлыкова Е. В. [8], однако данная модель частично базируется на изменении показателей по отношению к прошлому отчетному периоду, что не является основным ориентиром в современных условиях.

По результатам исследования среднего бизнеса за 2015-2019 гг. было определено, что 35\% предприятий среднего бизнеса использовали агрессивную модель управления, 52\% - умеренную, 13\% предприятий применяют консервативную модель. Недостаток финансирования до периода пандемии испытывало 59\% среднего бизнеса $[9,10]$. Но он во многом решался грамотными стратегиями финансирования. На сегодняшний день ситуация близка к критической, пересмотра требуют не только модели финансирования, но и изменившаяся структура спроса.

Если бизнесу не удается генерировать достаточный уровень прибыли, характер долговых обязательств с фиксированными затратами в современных условиях может оказаться слишком рискованной. Необходимо в первую очередь минимизировать риска банкротства. Поэтому, при выборе стратегии финансирования необходимо включение в анализ издержек финансовой неустойчивости. Речь не идет о финансовых затруднениях, с периодичностью возникающих в бизнесе [11]. На современном этапе развития экономики наиболее остро встает ситуация долгового навеса, когда уровень прибыли растет медленнее уровня обязательств. Долговой навес, по мнению многих исследователей является одним из важных факторов, ведущих к кризисному состоянию [12]. В нестабильных условиях, когда сложно прогнозировать денежный поток, 
достаточный для погашения обязательств или использования возможности рефинансирования долга, финансовый рычаг не должен вызывать реализации условных издержек финансовых затруднений.

Включение в анализ издержек потенциального банкротства можно разделить на конфликты с кредиторами (специфические прямые и косвенные издержки) и потерю конкурентных преимуществ (косвенные издержки). Конфликты с кредиторами включают в себя судебные издержки, издержки реорганизации, санации, ликвидации; издержки по оплате экспертов по финансовому оздоровлению; управленческие: специфические инвестиционные решения, как следствие «давления долга». Потеря конкурентных преимуществ включает издержки клиентов: снижение качества, уровня обслуживания и т.п.

Эффект применения инструментов заемного финансирования можно определить, используя расширенную трактовку финансового рычага:

$$
R O E=R O O A+\left(R O N O A-k_{d}\right) \times D / S+\left(R O O A-k_{O}\right.
$$
$\mathrm{x} O L / N O A X)$

$D / S$ - финансовый рычаг;

$O L / N O A$ - рычаг краткосрочных обязательств;

$k_{d}$ - посленалоговая ставка по займам;

$\kappa_{o}$ - аналитическая ставка по «беспроцентным» обязательствам;

$\kappa_{0} \leqslant k_{d}$

В то же время, при принятии решения о выборе инструментов финансирования, нужно учитывать, что влияние структуры капитала на стоимость компании проявляется с ростом неопределенности и несовершенств рынка. Включение в анализ издержек финансовой неустойчивости на современном этапе играет особую роль из-за превалирования агентских конфликтов, асимметрии информации, не прогнозируемых условий предоставления займов. Проявление влияния зависит от особенностей отрасли, операционной деятельности компании, корпоративного управления.

В целом, выбор той или иной модели управления финансирования бизнеса должно определяться индивидуально, с учетом особенностей факторов спроса. Так как в любом правиле существуют исключения [13]. Так, например, при развитии инфляции, снижающей платежеспособность предприятий во время экономическо- го спада, вместо ожидаемого роста доли самофинансирования происходит увеличение доли привлеченных средств, если базовая ставка рефинансирования ниже уровня инфляции, как это имеет место в ЕС, США, Японии, Китае [14,17].

Стратегия финансирования бизнеса должна обеспечивать приемлемый уровень прибыли и риска. Важное значение имеет выбор стратегии: как с точки зрения стратегических целей инвестиционной привлекательности бизнеса, так и с с позиции перспективного финансового планирования, что достаточно затруднено в современных условиях неопределенности. На сегодняшний день нет универсальных стратегий финансирования среднего бизнеса. Однако, включение в анализ основных факторов, таких, как уровень спроса, издержки финансовой неустойчивости, анализ преимуществ и недостатков современных финансовых инструментов позволит разработать универсальную модель финансирования конкретного бизнеса.

Выбор стратегии финансирования бизнеса должно обеспечивать решение следующих задач. Во-первых, обеспечение платежеспособности. Риск неплатежеспособности велик у бизнеса, не имеющего достаточного объема оборотного капитала. Во-вторых, обеспечение достаточного объема, рентабельности и структуры активов. Любое управленческое решение, касающееся движения денежных средств и определения их уровня, возникновения задолженности и изменения товарных запасов, необходимо рассматривать как с двух позиций:

1) оптимальной структуры оборотного капитала,

2) рентабельности данного вида активов.

Среднему бизнесу с большим объемом выручки необходимо использовать умеренную или консервативную стратегию финансирования бизнеса, трансформируя ее под новые реалии. Рискованную, агрессивную стратегию финансирования бизнеса имеет смыл адаптировать только при низком уровне выручки, с учетом положительной динамике при анализе уровня спроса.

В среднем бизнесе, еще до кризиса, в часто встречалась агрессивная стратегия финансирования. До пандемии прослеживалась зависимость между уровнем выручки, скоростью оборота капитала и выбором стратегии финансирования. Умеренную или консервативную стратегию финансирования бизнеса использо- 
вал бизнес с выручкой более 1 млрд. рублей и высокой оборачиваемостью. Остальная часть среднего бизнеса использовала умеренноагрессивную и агрессивную стратегию. В среднем оптимальной являлась структура, с дебиторской задолженностью до 20\%, высоким уровнем запасов. На сегодняшний день, включение в анализ издержек финансовой неустойчивости расширенной трактовки финансового рычага, позволят определить оптимальную модель бизнеса в частности. Исходя из условий деятельности бизнеса, уровня его развития и учета спроса и предложения необходимо корректировать эту структуру.

\section{Библиографический список}

1. Mironova M.D, Nugumanova L.F, Markova S.V, Company management based on predictable sustainability of activities in an environment of uncertainty//International Multidisciplinary Scientific GeoConference Surveying Geology and Mining Ecology Management, SGEM. - 2018. - Vol.18, Is.5.3. - P.143-150

2. Bagautdinova N.G., Galieva G. T., Pakhmutov Ya.O., Pratchenko O. V.(2014). Methods of Regulation of Processes of Innovation Business Development. Mediterranean Journal of Social Sciences. Vol.5. No12. p.75-80.

3. Шигабиева А. М. Предпосылки, принципы и цели финансового менеджмента в управлении денежными потоками // Казанский экономический вестник. - 2018. - № 3(35). - С. 46-51

4. Никандрова Р. С. Оборотный капитал: эволюция трактовок // Международный журнал естественных и гуманитарных наук. - 2016. - № 1.- часть 8. - С. 262-266.

5. Кондратова С.В., Умрихина М. В. Управление оборотными средствами автомобильного дилерского центра в новой экономике // Известия МГТУ «МАМИ»._-2014. - № 3(21). - Том 5.- С. 10-16.

6. Токарева Г.Ф., Багаутдинова И. В. Количественная оценка типа моделей управления величиной оборотного капитала и источниками его финансирования // Российское предпринимательство. - 2014. - № 19(265). C. $93-102$.

7. Alla Podgornaya, Svetlana Grudina, Sofiya Avdonina. Anticrisis Potential Of Innovative Enterprises (Russia and Germany Case Study)//The Proceedings of 6th World Conference on educational Sciences. (Malta 2 June 2015).Volume 191.- P. 275-279.

8. Башлыков Е.В.Управление оборотным капиталом промышленного предприятия: автореф. дис. ... канд. экон. наук: 08.00.05.- Екатеринбург, 2007.-24 с.

9. Обзор автомобильного рынка России в 2018 г. и перспективы развития // URL: https://www.pwc.ru/ru/ materials/auto-press-briefing.pdf (дата обращения: 5.06.2020)

10. Центр раскрытия корпоративной информации. URL: https://unecon.ru/info/centr-raskrytiya-korporativnoyinformacii-godovye-i-kvartalnye-otchety-konsolidirovannaya (дата обращения: 5.06.2020)

11. Podgornaya A.I., Grudina S. I., Avdonina S. G. An Enterprise Flexible Development Model //Procedia Economics and Finance Volume 24, 2015, Pages 519-522.

12. Теплова Т.В., Григорьева Т. И.. Ситуационный финансовый анализ. Москва: Издательский дом ГУ ВШЭ, 2006.

13. Бикчантаева Д.К. Современные подходы к управлению источниками финансирования/ Бикчантаева Д.К., Гузельбаева Г. Т. //Экономика в меняющемся мире III Всероссийский экономический форум с международным участием - Казань 2019.- С.118-120.

14. Зотов В.П., Жидкова Е. А. Определение сущности оборотного капитала в современной экономике // Техника и технология пищевых производств. - 2014. - № 2.- С. 135-139.

15. Факторы повышения конкурентоспособности региона. Аксенов И.А., Валеева Ю.С., Галимова Э.И., Демьянова О.В., Дюдина О.В., Жуков А.С., Захаров С.В., Казначевский Б. А., Макарова Е. С., Никифоров О.А., Нечитайлов А. С., Николаев М. В., Романова Т. Е., Саубанов К. Р., СербиновскийБ.Ю., СултановаД.Ш., Тесленко И.Б., Тимошенко О.В., ТкачА.В., ФахрутдиноваЕ.В. и др. Казань, 2018..- 300с.

16. Fakhrutdinova E.V., Kolesnikova J.S., Fakhrutdinov R. M., Yagudin R. H. Shadow economy in Russia// Mediterranean Journal of Social Sciences. 2015. T. 6. № 1 S3. C. 67-72.

17. Zhukovets Tatiana, Strelnik Eugeniia, Usanova Diana, regression analysis of key efficiency indicators in the context of corporate financial management based on the indicator of the economic value added (EVA)//National academy of managerial staff of culture and arts herald.-2017.- Vol., Is.4.- P.202-206. 